The Journal of Laryngology \& Otology

http://journals.cambridge.org/JLO

Additional services for The Journal of Laryngology \& Otology:

Email alerts: $\underline{\text { Click here }}$

Subscriptions: $\underline{\text { Click here }}$

Commercial reprints: Click here

Terms of use : $\underline{\text { Click here }}$

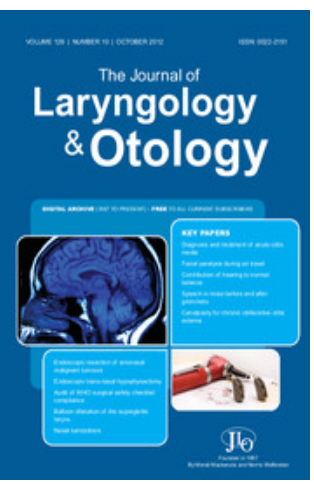

\title{
NdYAG laser treatment of a glomus tympanicum tumour
}

Philip J. Robinson, Henry R. Grant and Stephen G. Bown

The Journal of Laryngology \& Otology / Volume 107 / Issue 03 / March 1993, pp 236 - 237

DOI: 10.1017/S0022215100122728, Published online: 29 June 2007

Link to this article: http://journals.cambridge.org/abstract_S0022215100122728

How to cite this article:

Philip J. Robinson, Henry R. Grant and Stephen G. Bown (1993). NdYAG laser treatment of a glomus tympanicum tumour. The Journal of Laryngology \& Otology, 107, pp 236-237 doi:10.1017/S0022215100122728

Request Permissions : $\underline{\text { Click here }}$ 


\title{
NdYAG laser treatment of a glomus tympanicum tumour
}

\author{
Philip J. Robinson, F.R.C.S., ${ }^{*}$ Henry R. Grant, F.R.C.S.,* Stephen G. Bown, F.R.C.P.† (London)
}

\begin{abstract}
Glomus tympanicum tumours are highly vascular tumours of the middle ear. Their removal by conventional surgical methods requires an extensive procedure in many cases, often with ossicular disarticulation to allow adequate exposure prior to the 'chaotic' and haemorrhagic event of tumour removal. This paper reports on the use of an NdYAG laser in a case of a large glomus tympanicum tumour. The laser facilitated a transcanal approach, avoided ossicular disarticulation and allowed accurate and almost bloodless ablation of the entire tumour.

The NdYAG laser appears to be a very useful treatment modality in the management of these highly vascular tumours. Care should be taken to avoid accidental energy transmission to the cochlea.
\end{abstract}

Key words: Glomus tympanicum tumour; Laser, NdYAG

\section{Introduction}

Glomus tympanicum tumours (paragangliomas) are highly vascular tumours arising from the paraganglion situated near the middle ear surface of the promontory and are confined to the middle ear. They must be differentiated radiologically (Phelps and Stansbie, 1988) from the more extensive glomus jugulare tumours which arise from the paraganglion in the wall of the jugular bulb and invade into the petrous bone and middle ear. Surgical excision is the standard treatment for glomus tympanicum tumours, requiring extensive procedures in the majority of cases and always associated with marked haemorrhage during tumour removal.

This paper reports a case in which a large glomus tympanicum tumour was removed by ablation with the NdYAG laser via a transcanal approach.

\section{Case report}

A 60-year-old lady presented with a five-year history of leftsided pulsatile tinnitus and gradual hearing loss. She had no other symptoms to suggest either an extensive tumour, for example hoarseness, dysphagia, aspiration, facial, shoulder or tongue weakness or a neuroendocrinologically active tumour, for example headaches, palpitations, flushing or labile hypertension. Otoscopic examination revealed a large, pulsatile, vascular lesion behind the tympanic membrane almost filling the middle ear. The margin of the tumour was only visible superiorly. There were no cranial neuropathies present and no evidence of any synchronous lesions.

Pure tone audiometry, at presentation, showed a $25 \mathrm{~dB}$ leftsided conductive hearing loss with no evidence of any sensorineural loss. A CT scan with contrast enhancement demonstrated a soft tissue mass confined to the middle ear with no evidence of erosion of the skull base (thus excluding the diagnosis of a glomus jugulare tumour). Digital subtraction angiography of the left carotid arterial system demonstrated a highly vascular mass in the left middle ear cavity (Fig. 1).

Under a general anaesthetic, the middle ear was exposed by an endaural, transcanal approach raising a tympano-meatal flap.
The flap was carefully elevated off the surface of the tumour to avoid undue haemorrhage. The tumour was found to extend from the margins of the eustachian tube orifice anteriorly to the facial recess posteriorly, filling the hypotympanum inferiorly and extending up to the level of the horizontal portion of the facial nerve superiorly. It was draped over the incudo-stapedial joint. A piece of tumour was sent for histology, which confirmed the diagnosis of a paraganglionoma.

A NdYAG laser (MODEL 4060, MBB, Munich) was used to deliver laser light via a $0.4 \mathrm{~mm}$ flexible fibre, held in a $2.5 \mathrm{~mm}$ Teflon catheter.

This laser probe was held 2-3 millimetres above the tumour surface using the low power red light of the coaxial helium neon laser for aiming. The NdYAG laser was first used at 1 watt for 1-2 sec and the power slowly increased between shots until ther-

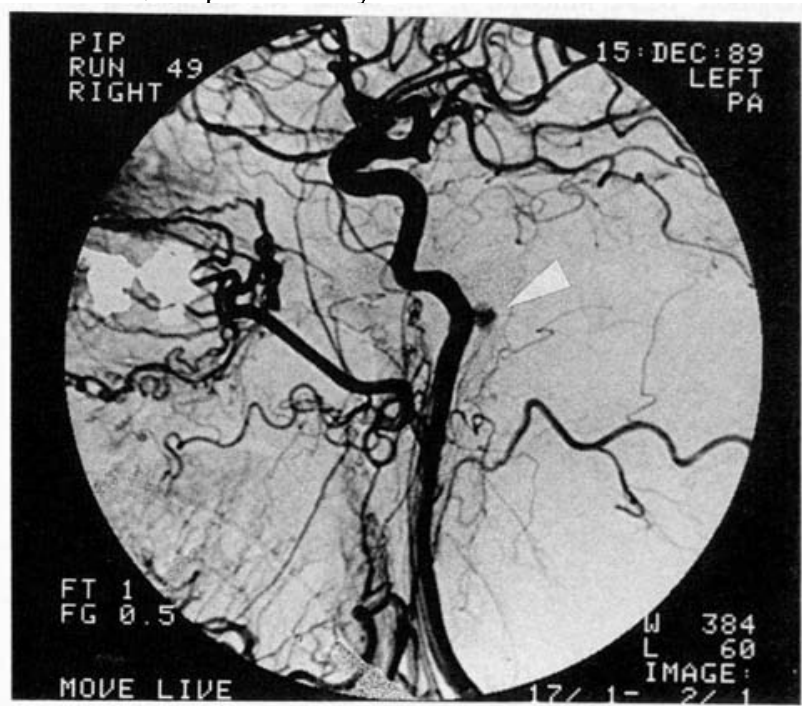

FIG. 1

Digital subtraction angiogram of the left carotid arterial system, demonstrating the glomus tympanicum tumour (arrow).

From The Ferens Institute of Otolaryngology, University College and the Middlesex Hospital* and the National Medical Laser Centre. University College Hospitalt, London.

Accepted for publication: 26 October 1992. 


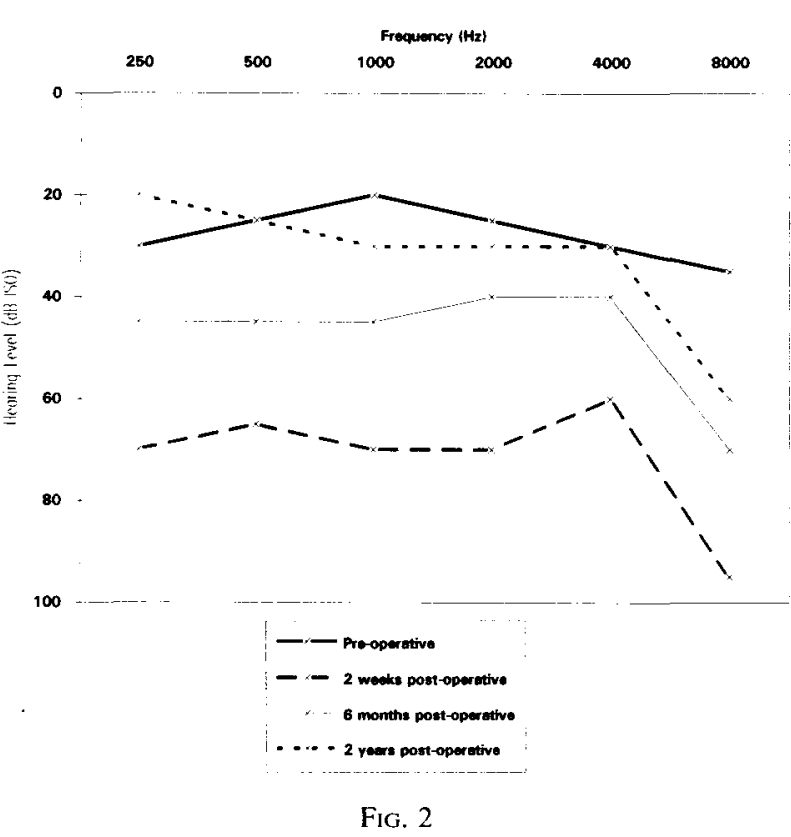

Pure tone (air conduction) thresholds, pre- and post-operatively.

mal coagulation could be seen by whitening and contraction of the tumour surface. This occurred at 5-6 watts. As the tumour contracted in the centre, the peripheral margins were drawn into the field of view and could also be treated with this power level. By using repeated laser shots on the same site, small volumes of coagulated tumour could be vaporized, but this was done with caution to minimize the risk of damage to the underlying structures. When all visible tumour had been coagulated, the coagulated tissue was manipulated by gentle traction to bring the remaining parts of the tumour into view for treatment.

The tumour was coagulated and thus removed from the incudo-stapedial joint without the need for any manipulation. Tumour was also removed from the round window niche but, retrospectively, it is possible that some energy entered the cochlea at this stage resulting in some hair cell damage.

Tumour destruction was almost bloodless until the last piece of tissue was coagulated when the feeding vessel was reached. As the tumour had been completely ablated it was straightforward to control this haemorrhage and the blood loss for the whole procedure was only $50 \mathrm{ml}$. The tympan-omeatal flap was replaced and the endaural incision closed.

Post-operatively the patient reported that the pulsatile tinnitus had completely disappeared but that she was experiencing constant high pitched tinnitus. An audiogram taken two weeks postoperatively revealed that there had been some cochlear loss with an average threshold of $66 \mathrm{~dB}$ (at $500 \mathrm{~Hz}, 1 \mathrm{kHz}, 2 \mathrm{kHz}$ and $4 \mathrm{kHz}$ ). Over the following six months the tinnitus improved to an acceptable level associated with a gain in her hearing to within $20 \mathrm{~dB}$ of the pre-operative level. The hearing level continued to improve over the next 18 months, returning to the preoperative level (Fig. 2). At two years post-operatively the tympanic membrane is well healed and there is no sign of recurrence. She has very occasional episodes of high pitched tinnitus which do not bother her. There were no other post-operative complications and, in particular, she had normal facial movement and no vestibular disturbance.

\section{Discussion}

To our knowledge, this is the first reported case of a glomus tumour being treated by a NdYAG laser. The standard treatment for glomus tympanicum tumours is excisional surgery, often requiring extensive procedures. In a recent report (Jackson et al., 1989) on the surgical treatment of 60 patients with glomus tympanicum tumours, 78 per cent required an extended facial recess approach, the external auditory canal wall was removed in 12 per cent and only 10 per cent were removed by a transcanal approach, 21 per cent required ossicular disarticulation. Total tumour removal was only achieved in 90 per cent. The reported purpose of this extensive surgery is to obtain adequate exposure to vital middle ear anatomy prior to the 'chaotic' and haemorrhagic event of tumour removal.

Sensorineural hearing loss, ossicular damage and excessive bleeding are all complications of the conventional surgical approaches.

Radiotherapy has been proposed as primary treatment for glomus tympanicum tumours (Konefal et al., 1987). However this treatment modality has been reserved mainly for larger, irresectable lesions, especially those found to be involving the internal carotid artery and for patients too infirm to undergo extensive surgery. Use of the laser might allow a lesser procedure to be carried out in an elderly or infirm patient.

The histology of a glomus tympanicum (paraganglioma) resembles a carotid body tumour; indeed, the first description of these tumours was by Rosenwasser (1945), who referred to them as carotid body tumours of the middle ear and mastoid. The tumour consists of epithelioid uniform cells, often forming into clusters, separated by numerous blood vessels (Michaels, 1987).

The wavelength of the NdYAG laser penetrates vascularized tissue well, so the depth of coagulation can be controlled precisely by the amount of laser energy delivered. The ease and bloodless nature of the coagulation raises the question of whether there would be a place for its use in resection of the larger glomus jugulare tumours.

In this case, use of the NdYAG laser allowed a transcanal approach in a lesion where initially the margins were not completely visible; it avoided anatomical disruption of the ear such as ossicular disarticulation or removal of the posterior canal wall and avoided extended surgery with its increased risk of complications such as facial nerve palsy. The most significant advantage was the minimal bleeding which allowed tumour ablation to occur with good visualization of all the important structures and avoided the chaotic event of tumour removal referred to by Jackson et al. (1989).

The cost of the laser use in this case was some cochlear loss which may have resulted from absorption of energy through the round window and subsequent hair cell loss. This resulted in a change in character of the tinnitus but this improved over the first six post-operative months to an acceptable level and at 12 months was no longer a problem.

\section{Conclusion}

The NdYAG laser appears to be a useful treatment modality in the management of these highly vascular tumours although care should be taken when treating near the round window to avoid accidental energy transmission into the cochlea.

\section{References}

Jackson, C. G., Welling, D. B., Chironis, P., Glassock, M. E., Woods, C. I. (1989) Glomus tympanicum tumours: contemporary concepts in conservation surgery. Laryngoscope 99: 875-884.

Konefal, J. B., Pilepich, M. V., Spector, G. J. (1987) Radiation therapy in the treatment of chemodectomas. Laryngoscope 97: 1331-1335.

Michaels, L. (1987). Ear Nose Throat Histopathology, SpringerVerlag, Berlin, Heidelberg, p 71.

Phelps, P. D., Stansbie, J. M. (1988) Glomus jugulare or tympanicum? The role of CT and MR imaging with Gadolinium DTPA. Journal of Laryngology and Otology 102: 766-776.

Rosenwasser, H. (1945) Carotid body tumour of the middle ear and mastoid. Archives of Otolaryngology 41: 64-67.

Address for correspondence:

Philip J. Robinson, F.R.C.S.,

21 Chatsworth Road,

Chiswick,

London W4 3HY. 